\title{
Toxicity of Essential Oils to Stored Product Pest and Application to Extrusion Coating Film for Extend Rice Storage Life
}

\author{
Udomporn Pangnakorn ${ }^{1,}$, , Sombat Chuenchooklin ${ }^{2}$ \\ ${ }^{1}$ Department of Agricultural Science, Faculty of Agriculture Natural Resources and Environment/Center of Excellence on Post Harvest, \\ Naresuan University, Phitsanulok, Thailand \\ ${ }^{2}$ Department of Civil Engineering, Faculty of Engineering/Center of Excellence in Water Resources, Naresuan University, Phitsanulok, \\ Thailand
}

Email address:

udompornp@nu.ac.th (U. Pangnakorn), sombatc@nu.ac.th (S. Chuenchooklin)

${ }^{*}$ Corresponding author

\section{To cite this article:}

Udomporn Pangnakorn, Sombat Chuenchooklin. Toxicity of Essential Oils to Stored Product Pest and Application to Extrusion Coating Film for Extend Rice Storage Life. International Journal of Environmental Monitoring and Analysis. Vol. 6, No. 2, 2018, pp. 65-70.

doi: 10.11648/j.ijema.20180602.14

Received: April 19, 2018; Accepted: May 22, 2018; Published: June 20, 2018

\begin{abstract}
The toxicity of essential oils and wood vinegar was tested on stored-product insects that infest rice. The essential oils from 5 plants, lemon grass Cymbopogon citratus Stapf, citronella grass Cymbopogon nardus Linn, pomelo peel Citrus maxima (Burm) Merr, eucalyptus Eucalyptus globulus Labill, and kaffir lime peel Citrus hystrix, were extracted by stream distillation. Raw wood vinegar was purified by filtering. Toxicity to red flour beetle Tribolium castaneum Herbst (Coleoptera: Tenebrionidae) was evaluated under laboratory conditions using topical application method (contact toxicity) and residual exposure method (fumigant toxicity). Overall, exposure to residual volatiles achieved higher mortality than droplet application. Kaffir lime peel achieved the highest mortality; $60 \%$ by topical application and $100 \%$ by residual exposure. A lower toxicity was found for lemon grass, citronella grass, eucalyptus and wood vinegar. Thereafter, kaffir lime peel oil extrusion coated onto plastic film that was used for storing packaged rice. Rice was stored in the bags for one month and pest infestations were quantified. The treatments showed no infestation of red flour beetle T. castaneum Herbst. Additional, the treatments showed significant protection against the 2 other stored product insects, including saw-toothed grain beetle, Oryzaephilus surinamensis L and rice weevil Sitophilus oryzae Linn. The results suggest that kaffir lime oil may be useful as a grain protectant against rice-infesting insects when used as a coating for bags made of extrusion film.
\end{abstract}

Keywords: Essential Oils, Extrusion Coating, Stored Product Insects, Rice Storage Life

\section{Introduction}

Red flour beetle Tribolium castaneum Herbst (Coleoptera: Tenebrionidae), distributed worldwide, is the most destructive pest of stored products. It can readily infest grains damaged in the harvesting operation [1] and has a high reproductive potential [2]. Control relies heavily on the use of synthetic insecticides and fumigants, which has led to problems such as disturbances of the environment, increasing costs of application, pest resurgence, pest resistance to pesticides and lethal effects on non-target organisms in addition to direct toxicity to users. An alternative to synthetic pesticides is the use of essential oils; the toxicity of a large number of essential oils and their constituents has been evaluated against a number of stored-product insects [3]. According to consumers demand more natural processed products with long shelf-life but without chemical preservatives [4]. Essential oils are used in the foodstuff packaging material [5] or as plant and crop protectants [6]. Edible films or coatings have provided an interesting and often essential complementary means for controlling the quality, stability of food products and extend shelf-life [7]; [8]. Many essential oils are known to have fumigant activity against eggs, larvae and adults of Tribolium castaneum, and 
the toxicity progressively increased with increased exposure times and concentrations [9].

Lemon grass Cymbopogon citratus Stapf, Family Poaceae, is a widely used herb in tropical countries, especially in Southeast Asia. The essential oil of the plant is used in aromatherapy. It is claimed to have antidepressant, antioxidant, antiseptic, astringent, bactericidal, fungicidal, nervine and sedative properties. Some of the reported phyto-constituents are essential oils that contain citral $\alpha$, citral $\beta$, nerol geraniol, citronellal, etc. $[10,11]$.

Citronella grass (Cymbopogon nardus Linn), Family Gramineae, is the source of commercial citronella oil. Citronella oil is very widely used as an aromatic constituent of perfumery and cosmetic products. The complete oil is used as an insect repellent for humans and pets and can be applied in soap, detergents, household insecticides and technical products. In Thailand, a preparation of crude citronella oil mixed with leaves of neem (Azadirachta indica A. Juss) and rhizomes of Alpinia galanga (L.) is applied as a biopesticide in agriculture. The United States Environmental Protection Agency considers citronella oil a biopesticide with a non-toxic mode of action (EPA 1993) [12].

Eucalyptus Eucalyptus globulus Labill, Family Myrtaceae, is native to Australia and has been introduced in the past few centuries to other parts of the world including India, Europe and South Africa. Eucalyptus essential oil extracted from eucalyptus leaves has most of the properties of a typical volatile oil, also having powerful medicinal properties. Eucalyptus' effectiveness respiratory applications overshadows its other uses. It is antibacterial, anti-viral, anti-

fungal, and anti-inflammatory, which means it is useful for many ailments [13].

Pomelo Citrus maxima (Burm) Merr, Family Rutaceae, is an indigenous plant in tropical parts of Asia. The pulp is stated to possess a number of therapeutic properties as reported in ancient and medieval literature: an appetizer, antitoxic, cardiac stimulant, and stomach tonic [14].

Kaffir lime Citrus hystrix, family: Rutaceae is a citrus fruit native to tropical Asia, including Thailand. Its fruit and leaves are used in Southeast Asian cuisine and its essential oil is used in perfumery [15]. The essential oils have very complex natural mixtures that can contain 20 to 60 components. They have been used widely as bactericides, virucides, fungicides, antiparasites, and insecticides in various applications [16].

Wood vinegar is a byproduct from charcoal production. Raw wood vinegar has approximately 200 chemicals compounds, such as acetic acid, formaldehyde, ethyl-valerate, phenol, methanol, tar, and etc. [17]. It has been used for organic farming and showed high efficiency as an insect repellent and had the highest efficacy in reducing pest infestation on soybean [18].

This study was carried out to investigate the toxicity properties of essential oils from these species and wood vinegar against red flour beetle $T$. castaneum Herbst. The high efficiency of the essential oils was selected and applied to extrusion coating film for rice storage life.

\section{Material and Method}

\subsection{Insect Preparation}

Red flour beetles Tribolium castaneum Herbst were collected from rice storage silos in Phitsanulok province, Thailand, and were laboratory-reared with eggs laid on grain rice and hatched at room temperature. Two-day old adults of red flour beetle were selected and prepared for bioassay tests.

\subsection{Plants Extract Preparation}

Fresh lemon grass, citronella grass, pomelo peel, eucalyptus leaves and kaffir lime peel were collected, cut into small pieces and air dried at $25^{\circ} \mathrm{C}$ for sample extraction using steam distillation. $500 \mathrm{~g}$ dried sample of each plant were placed in a distillation flask with water and heated to boiling point. The flask was allowed to boil for 5 hours until the distillation was completed. The distillate was collected in a separating funnel in which the aqueous portion was separated from the essential oils. The essential oils were collected and kept in a stoppered cylinder at $4^{\circ} \mathrm{C}$ and was diluted for testing on the red flour beetle. Tween 80 was used for emulsion to stabilize the essential oils before testing.

\subsection{Preparation and Purification Method of Raw Wood Vinegar}

Wood vinegar is made from burning fresh wood in a charcoal kiln (or Iwate kiln). The wood was burnt at $120-430^{\circ} \mathrm{C}$. The outside air when passing through the chimney to produce pyroligneous liquor cooled the smoke from carbonization. The hot steam condensed into liquid known as raw wood vinegar was collected and was purified by filtering before use.

\subsection{Insects Bioassay Test}

Two methods were used in the experiment: 1) Topical Application assesses contact toxicity; a $0.5 \mu \mathrm{l}$ droplet of the diluted essential oil at a ratio of 1:9 for each treatment was placed on the head area of the red flour beetle with a micro-applicator. The treated insects were moved to a cup with grain rice (10 insects /cup) for observation of mortality. 2) Residual Exposure assesses fumigant potential; the diluted essential oil at a ratio of 1:9 was sprayed on filter paper and placed on a petri dish. Red flour beetles were added after the treatment evaporated (10 insects / petri dish). Each treatment was carried out in 4 replicates. Mortality was observed 12, 24, 36, 48 and 72 hours after adding the beetles. When control mortality occurred on the experimental test, the mortality was corrected by Abbott's formula [19]:

$$
\% \text { Mortality }=\frac{\% \text { test mortality }-\% \text { control mortality }}{100-\% \text { control mortality }} \times 100
$$




\subsection{Extrusion Coating Film with the Essential Oils}

In the extrusion coating process, low-density polyethylene (LDPE) is melted under heat and pressure in an extruder and the molten polymer is extruded through a slit die as a thin film. This film, at high temperature, is drawn down and coated by the selected essential oils (Figure 1). In this study, the high toxicity: kaffir lime oil, lemon grass oil, and citronella grass oil were selected for extrusion coating (water as control treatment) with $1 \%$ concentration. Only the kaffir lime oil was diluted in various concentration at $1 \%, 2 \%, 3 \%$ and $4 \%$. The selected essential oils were fed continuously over the rubber pressure and was rapidly cooled by the chill roll and was then taken up by a wind-up mechanism. The extrusion coated film was cut to form bags $(10 \times 15 \mathrm{~cm})$. One hundred grams of rice purchased from a supermarket was placed in each unsealed bag. Each concentration treatment was replicated three times. Infestation of stored products insects was observed after storage at room temperature for 1 month.

\subsection{Statistical Analysis}

The significance of treatments was calculated by one way Analysis of Variance (ANOVA) and effective treatment was separated by the Duncan's New Multiple Ranges Test (DMRT). Differences between means were considered significant at $\mathrm{P}<0.05$.

\section{Results and Discussion}

\subsection{Toxicity of Essential Oils on Red Flour Beetle Tribolium Castaneum Herbst}

Table 1. Toxicities of essential oils and wood vinegar on red flour beetle Tribolium castaneum Herbst by topical application.

\begin{tabular}{lllllll}
\hline Treatment & \% Mortality & & & & \\
\hline & $\mathbf{1 2 h}$ & $\mathbf{2 4 h}$ & $\mathbf{3 6 h}$ & $\mathbf{4 8 h}$ & $\mathbf{7 2 h}$ & df \\
\hline Control (water) & 0 & 0 & 0 & 0 & $0^{\mathrm{c}}$ & $\mathrm{ns}$ \\
Lemon grass & 6.67 & 16.67 & 23.34 & 26.67 & $26.67^{\mathrm{ab}}$ & $\mathrm{ns}$ \\
Citronella grass & 0 & 16.67 & 20.0 & 20.0 & $20.0^{\mathrm{ab}}$ & $\mathrm{ns}$ \\
Pomelo peel & 0 & 3.33 & 6.66 & 6.66 & $6.66^{\mathrm{bc}}$ & $\mathrm{ns}$ \\
Eucalyptus & 3.33 & 6.66 & 13.33 & 16.66 & $16.66^{\mathrm{ab}}$ & $\mathrm{ns}$ \\
Kaffir lime peel & 16.67 & 26.67 & 43.34 & 60.01 & $60.01^{\mathrm{a}}$ & $*$ \\
Wood vinegar & 0 & 6.67 & 6.67 & 10.0 & $10.0^{\mathrm{b}}$ & $\mathrm{ns}$ \\
\hline
\end{tabular}

ns $=$ non significant; $*$ = significant difference, means (followed by the same letter) are not significantly different at $5 \%$ level by DMRT

Table 2. Toxicities of essential oils and wood vinegar on red flour beetle Tribolium castaneum Herbst by residual exposure.

\begin{tabular}{|c|c|c|c|c|c|c|}
\hline Treatment & $\% \mathrm{Mo}$ & & & & & \\
\hline & $12 \mathrm{~h}$ & $24 h$ & $36 \mathrm{~h}$ & $48 \mathrm{~h}$ & $72 \mathrm{~h}$ & df \\
\hline Control (water) & 0 & 0 & 0 & 0 & $0^{\mathrm{c}}$ & ns \\
\hline Lemon grass & 30.0 & 46.67 & 56.67 & 56.57 & $56.67^{\mathrm{ab}}$ & $*$ \\
\hline Citronella grass & 23.33 & 33.33 & 33.33 & 33.33 & $33.33^{\mathrm{b}}$ & ns \\
\hline Pomelo peel & 0 & 0 & 0 & 0 & $0^{\mathrm{c}}$ & ns \\
\hline Eucalyptus & 3.33 & 3.33 & 3.33 & 3.33 & $3.33^{\mathrm{c}}$ & ns \\
\hline Kaffir lime peel & 50.0 & 86.67 & 100 & 100 & $100^{\mathrm{a}}$ & $*$ \\
\hline
\end{tabular}

ns = non significant; $*$ = significant difference, means (followed by the same letter) are not significantly different at $5 \%$ level by DMRT

In this study, five essential oils were tested against the adult red flour beetle Tribolium castaneum Herbst in the laboratory using two methods, topical application to test contact toxicity and residual exposure to test fumigant toxicity. In general, toxicity was higher when the essential oils were used as fumigants. The three test substances that showed the highest contact toxicity (oils of kaffir lime, lemon grass and citronella grass) also showed the highest fumigant toxicity. Kaffir lime essential oil stood out as the most effective fumigant, achieving $100 \%$ mortality after 36 hours. Table 1 and 2 showed the tested essential oils, kaffir lime oil produced the highest toxicity in red flour beetle, followed by lemon grass and citronella grass. Topical application of kaffir lime essential oil led to $60.0 \%$ mortality after 48 hours and residual exposure achieved $100 \%$ mortality within 36 hours. Additional, the wood vinegar and pomelo peel oil treatments were least effective in the topical application experiments and had no effect on mortality in the residual exposure experiments. Therefore, essential oils have been shown to have higher fumigation toxicity than contact toxicity against the red flour beetle, T. castaneum [20]. Fumigation is a successful method of eradicating stored product pests present in food products. A number of studies have shown the fumigation effects of volatile oils against T. castaneum [21]; [22]. A direct comparison of the potency of contact toxicities of the essential oils could not be made because different experimental methods were employed.

\subsection{Application of the Selected Essential Oils on Extrusion Coating Film for Rice Storage Life}

For many years, different measures have been taken to 
reduce the number of pests attacking stored cereal grain. Essential oils are used as incorporated into the foodstuff packaging material [5] or as plant and crop protectants [23]. However, many of essential oils uses have been lost with time [24], therefore this study the applications of essential oils for packaged consumer food products requires extrusion coating process, including the appropriated formulation of the essential oils. According to kaffir lime given extract produced high mortality in the residual exposure trials followed by lemon grass and citronella grass. Consequently, essential oil of kaffir lime was diluted in various concentration from $1 \%$ to $4 \%$, meantime essential oil of lemon grass and citronella grass were tested only $1 \%$. All formulation of the essential oils was selected as a film coating that was used to produce plastic rice storage bags. The process of extrusion coating film with the three essential oils for rice storage life as shown on figure 1. Bags were filled with rice and were left unsealed for 1 month. Infestation with the target insect, Tribolium castaneum Herbst and other stored product pests was assessed after one months of storage. All of the treatments included control showed on infestation by Tribolium castaneum Herbst but showed a small infestation with had significantly protection Oryzaephilus surinamensis L. and Sitophilus oryzae Linn. Presume that use of extrusion coating films with essential oils shows potential to protect rice from infestation of the stored insects. After one month, all of treatments showed no infestation by red flour beetle as shown on Table 3. A small number of infestations of other stored product insects such as saw-toothed grain beetle Oryzaephilus surinamensis L. and rice weevil Sitophilus oryzae Linn were found in all of the treatments. The number of the 2 other stored product insects found on the coated bags was significantly less than the control $(\mathrm{P}<0.05)$. The degree of infestation by saw-toothed grain $\mathrm{x}$ to different from the essential oils treatment. Saw-toothed grain beetle response to the coated citronella grass oil, meantime rice weevil tend to respond to the coated citronella grass oil.

The essential oils may be a potential grain protectant by killing various life stages of $T$. castaneum through contact and fumigant actions [25]. Essential oils were also reported that have potential activity for stored product pest control could be used as a multipurpose pest controlling agent [26]. However, many of essential oils uses have been lost with time [24], hence this study the applications of essential oils for packaged consumer food products requires extrusion coating process. Although, the present work revealed that 1-month exposure of stored rice to volatile essential oils can reduce pest infestations. The present study extended the use of essential oils by using them as coatings applied to extruded film that was then used to form rice storage bags.

Various plastic films have been tested for their ability to protect products from insect infestation. The most important plastic materials in use for food packaging are polyethylene, polypropylene and polyester [27]. Shukla et al [28] reported that adults of red flour beetle, Tribolium castaneum (Herbst) was able to penetrate polyethylene with less than $0.08 \mathrm{~mm}$ in thickness. Generally, most of the stored-product insects enter packaged food through already existing holes or openings [28].

Based on this work, polyethylene is extruded as a thin web and coated by the essential oils: kaffir lime peel oil, lemon grass oil and citronella grass oil to extrusion coating film and formed into storage bags by unsealed. It may explain the presence of insects in packaged products before it was packaged, infestation of raw commodities or cross-infestation during processing.

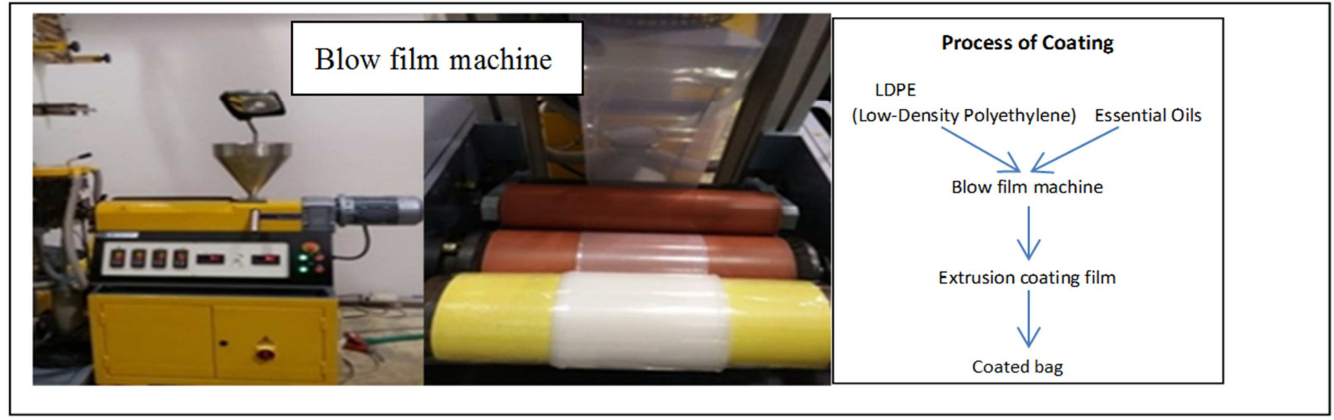

Figure 1. Process of extrusion coating film with essential oils for rice storage life.

Table 3. Efficiency of coated essential oils by extrusion coating film for rice storage life.

\begin{tabular}{llll}
\hline \multirow{2}{*}{ Treatment } & \multicolumn{3}{l}{ Infestation of stored product pests (number of insects) } \\
\cline { 2 - 4 } & Tribolium castaneum Herbst & Oryzaephilus surinamensis L. & Sitophilus oryzae Linn \\
\hline Control & 2 & $36.0^{\mathrm{a}}$ & $15.0^{\mathrm{a}}$ \\
Lemon Grass 1\% & 0 & $5.0^{\mathrm{b}}$ & $2.0^{\mathrm{b}}$ \\
Citronella grass 1\% & 0 & 1.0 & 1.0 \\
Kaffir lime 1\% & 0 & $9.0^{\mathrm{b}}$ & $5.0^{\mathrm{b}}$ \\
Kaffir lime 2\% & 0 & $6.0^{\mathrm{b}}$ & $8.0^{\mathrm{b}}$ \\
Kaffir lime 3\% & 0 & $5.0^{\mathrm{b}}$ & $5.0^{\mathrm{b}}$ \\
Kaffir lime 4\% & 0 & $5.0^{\mathrm{b}}$ & $2.0^{\mathrm{b}}$ \\
F-test & $\mathrm{ns}$ & $*$ & $*$ \\
\hline
\end{tabular}

$\mathrm{ns}=$ non significant; $*$ = significant difference, means (followed by the same letter) are not significantly different at $5 \%$ level by DMRT 


\section{Conclusion}

Fumigation is a successful method of eradicating stored product pests present in food products. Essential oils are used in a wide variety of consumer goods, they are used as incorporated into the foodstuff packaging material and crop protectants. This work results that the kaffir lime, lemon grass and citronella grass may be useful as a grain protectant against these insects when used as a coating for bags made of extrusion film. This approach could ensure reduced pest levels in domestically-stored rice and extended shelf-life, using environmentally-friendly and aromatic essential oils such as kaffir lime peel oil and lemon grass oil that already have acceptance as food ingredients. The possibility of applying essential oils as plastic film coatings to control insects in domestically-stored products may be worthy of further investigation.

\section{Acknowledgements}

The authors would like to express gratitude to the Higher Education Research of Thailand (HERT) for grants to carry out this research. We also would like to express our sincere gratitude to Naresuan University, Thailand, for funding support and providing laboratory facilities. Finally, we would like to thank the Dean of Faculty of Agriculture Natural Resources and Environment and the President of Naresuan University (NU) to permit some faculty members to participate in this research.

\section{References}

[1] Karunakaran, C., Jayas, D. S., and White, N. D. G., "Identification of wheat kernels damaged by the red flour beetle using X-ray image," Biosystems Engineering 87 (3): 2004, 267-274.

[2] Prakash, A. J., Rao, I. C., Pasalu and Mathur, K. C., "Rice Storage and insect pests management," BR Publishing Corporation, New Delhi, 1987, pp: 337.

[3] Paranagama P. A., Abeysekera, K. H. T., Abeywickrama, K. P., and Nugaliyadde, L., "Fungicidal and anti-aflatoxigenic effects of the essential oil of Cymbopogon citratus (DC.) Stapf. (lemongrass) against Aspergillus flavus Link. isolated from stored rice," Letters in Applied Microbiology 36: 2003, 1-5.

[4] Hyldgaard, M., Mygind, T., and Meyer, R. L., "Essential oils in food preservation: mode of action, synergies, and interactions with food matrix components," Frontiers in Microbiology 3, $2012,12$.

[5] Kuorwel, K. K., Cran, M. J., Sonneveld, K., Miltz, J., and Bigger, S. W., "Essential oils and their principal constituents as antimicrobial agents for synthetic packaging films," Journal of Food Science 76, 2011, R164-R177.

[6] Adorjan, B., and Buchbauer, G., "Biological properties of essential oils: an updated review," Flavour and Fragrance Journal 25, 2010, 407-426.

[7] Guilbert, S., Gontard, N., and Cuq, B., "Technology and applications of edible protective films," Packaging Technology and Science, November 1995. Vol. 8 (6): 1995, 339-346.

[8] Salgado, P. R., López-Caballero, M. E., Gómez-Guillén, M. C., Mauri, A. N., and Montero, M. P., "Sunflower protein films incorporated with clove essential oil have potential application for the preservation of fish patties," Food Hydrocolloid 33, 2013, 74-84.

[9] Islam, M. S., Mahbub Hasan, M., Xiong, W., Zhang, S. C., and Lei, C. L., "Fumigant and repellent activities of essential oil from Coriandrum sativum (L.) (Apiaceae) against red flour beetle Tribolium castaneum (Herbst) (Coleoptera: Tenebrionidae)," Journal of Pest Science (2009) 82: 2009, 171-177.

[10] Gagan, S., Richa, S., Vivek, P., Narender, S., Bharpur, S., and Mann, A. S., "Scientific basis for the therapeutic use of Cymbopogon citratus, stapf (Lemon grass)," Journal of Advanced Pharmaceutical Technology and Research. 2011 Jan-Mar; 2 (1): 2011, 3-8.

[11] Mohd I. N., Bashir A. F., Ebenezar J., Javid A. B., Antibacterial activity of lemongrass (Cymbopogon citratus) oil against some selected pathogenic bacterias," Asian Pacific Journal of Tropical Medicine (2010) 535-538.

[12] Environmental Protection Agency (EPA) Integrated Risk. Information System, d-Limonene. CASRN (1993) 5989-27-5.

[13] Worwood, Valerie Ann. The Complete Book of Essential Oils \& Aromatherapy. New World Library, San Rafael, CA, 1991. P. 20-21.

[14] Arias, B. A., and Ramon-Laca, L., "Pharmacological properties of citrus and their ancient and medieval uses in the Mediterranean region," Journal of Ethnopharmacology, vol. 97, no. 2, 2005, pp. 89-95.

[15] Doreen S. H. NG., Rose, L. C., Suhaimi, H., Mohamad, H., Rozaini, M. Z. H., and Taib, M., "Preliminary evaluation on the antibacterial activities of Citrus hystrix oil emulsions stabilized by TWEEN 80 and SPAN 80 (PDF)," International Journal of Pharmacy and Pharmaceutical Sciences 3 (2011) (Suppl. 2).

[16] Bakkali F., Averbeck S., Averbeck D., and Idaomar M., "Biological Effects of Essential Oils," A Review. Food and Chemical Toxicology 2008; 46: 2008, 446-475.

[17] Yoshimura, H., and Hayakawa, T., "Acceleration effect of wood vinegar from Quercus crispula on the mycelial growth of some basidiomycetes," Transactions of the Mycological Society of Japan 32: 1991, 55-64.

[18] Pangnakorn, U., Watanasorn, S., Kuntha, C., and Chuenchooklin, S., "Effects of Wood Vinegar and Fermented Liquid Organic Fertilizer on Soybean (Srisamrong 1) in the Drought Season Cultivation," Journal of ISSAAS (The International Society for Southeast Asian Agricultural Sciences) Vol. 16 (2): 2010, 67-73.

[19] Abbott, W. W., "A method of computing the effectiveness of an insecticide," Journal of Economic Entomology 18, 1925, 265 267.

[20] Mondal, M., and Khalequzzaman, M., "Toxicity of essential oils against red flour beetle, Tribolium Castaneum (Herbst) (Coleoptera: Tenebrionidae)," Journal of Bio-Science. 14: 2006, 43-48. 
[21] Germinara, G. S., Rotundo, G., and Cristofaro, A. D., "Repellent and fumigant toxicity of propionic acid against adults of Sitophilus granarius (L.) and Sitophilus oryzae (L.)," Journal of Stored Products Research 43, 2007, 229-233.

[22] Negahban, M., Moharramipour, S., and Sefidkon, F., "Fumigant toxicity of essential oil from Artemisia sieberi Besser against three stored-product insects," Journal of Stored Products Research 43, 2007, 123-128.

[23] Adorjan, B., and Buchbauer, G., "Biological properties of essential oils: an updated review," Flavour and Fragrance Journal 25, 2010, 407-426.

[24] Hyldgaard, M., Mygind, T., and Meyer, R. L., "Essential oils in food preservation: mode of action, synergies, and interactions with food matrix components," Frontiers in Microbiology 3, (2012) 12.
[25] Mondal, M., and Khalequzzaman, M., "Toxicity of essential oils against red flour beetle, Tribolium Castaneum (Herbst) (Coleoptera: Tenebrionidae)," Journal of Bio-Science. 14: 2006 , 43-48.

[26] Polatoğlu, K., and Karakoç, O. C., Biologically Active Essential Oils against Stored Product Pests. Essential Oils in Food Preservation, Flavor and Safety. 2016. Retrieved from http://dx.doi.org/10.1016/B978-0-12-416641-7.00005-5.

[27] Paine, F., and Paine, H., Manual de envasado de alimentos. Madrid: Vicente AM Ediciones; 1993.

[28] Athanassiou, C. G, Riudavets J., and Kavallieratos, N. G., Preventing stored-product insect infestations in packaged-food products. Stewart Postharvest Review, 2011, 3:8. 